Revista Iberoamericana. Vol. LXII, Núm. 175, Abril-Junio 1996; 507-521

\title{
EL INDIVIDUALISMO COLECTIVO EN CÉSAR VALLEJO
}

\author{
POR \\ Horacio Machín \\ University of Nevada, Reno
}

no es muy difícil saber de dónde viene Vicente Huidobro, pero, ¿de dónde viene en cambio ese César Vallejo que escribe en Trujillo, Perú, los poemas que reunirá en 1922 en Trilce?

Ángel Rama, La riesgosanavegación delescritor exilado

\section{INTRODUCCIÓN}

Este trabajo tiene por objeto una lectura de la obra poétical de Vallejo (1918-1938) tomando como hilo conductor su individualismo colectivo. ${ }^{2}$ Dicha noción es aquí una hipótesis o ficción de trabajo que opera como un modelo analógico. Alude a un conjunto de estrategias simbólicas, presentes en toda la obra poética de Vallejo, que guardan una cierta regularidad y coherencia interna. Las mismas, responden no a una planeada búsqueda de calculados objetivos, sino al desarrollo de líneas de acción simbólica y socialmente orientadas, cuya intencionalidad político-cultural reviste un carácter fuertemente emotivo.

En lo que sigue, examino el individualismo colectivo en Vallejo y argumento que dicha configuración estético-ideológica resulta útil a la hora de preguntarse de dónde viene Vallejo y cuál es su proyección dentro del imaginario social hispanoamericano. Para ello, uso libremente desarrollos recientes del concepto de ideología y, en particular, las reflexiones teóricas de Pierre Bourdieu sobre el poder simbólico y de Fredric Jameson sobre la función utópica de la ideología.

VANGUARDIA Y ALQULMIA POÉTICA

En el poeta socialista, el poema no es, pues, un trance espectacular, provocado a voluntad y al servicio preconcebido de un credo o propaganda política, sino

\footnotetext{
' Dentro de la misma, focalizo la imbricación de lo social y lo textual.

${ }^{2}$ Esta noción de individualismo colectivo cobra un mayor alcance conceptual en oposición al "individualismo posesivo" que, según C. B. Macpherson, caracteriza al pensamiento político liberal. Véase C. B. Macpherson.
} 
que es una función natural y simplemente humana de la sensibilidad (César Vallejo, El arte y la revolución).

Deslindar el componente vanguardista en la poesía de Vallejo es una tarea que excede los límites de este trabajo. Aquí solamente señalo algunas dificultades como un paso previo al examen de su individualismo colectivo. Ángel Rama destaca dos vertientes dentro de las vanguardias latinoamericanas:

una cosmopolita que amasaría la tradición de la lengua con la audacia estética de la metrópolis y otra que se internaría dentro de la propia cultura buscando exacerbadamente una renovación formal en las oscuras fuentes nutricias ... la dificultad es mayor cuando nos acercamos a la línea de intrahistóricos latinoamericanos (Rama, La riesgosa navegación... 255-56).

Rama incluye a Vallejo en la vertiente "intrahistórica" (la que ofrece mayores dificultades) y dice que las dos "testimonian la ampliación plural que se está produciendo en América Latina" y sus propuestas se formulan paralelamente a la curva ascendente del modelo narrativo realista y en oposición a sus autores más representativos (Rama, La novela latinoamericana 99-202).

Hugo Verani destaca la sorprendente intolerancia hacia lo nuevo que experimenta Vallejo, "el poeta mas innovador de su generación", y dice:

Preocupado por la autenticidad cultural y por la poesía como producto genuino de la vida, Vallejo no se identifica con ninguna tendencia vanguardista y no pierde ocasión de expresar su desdén ... Ante todo desprecia el carácter elitista del arte de vanguardia ... distanciándose conscientemente de los programas de vanguardia. A pesar de ello, Trilce (1922) representa la ruptura más radical con las normas poéticas tradicionales (Rama, $\mathrm{La}$ riesgosa navegación...84).

Hay un cierto consenso por parte de la crítica (Foster \& Jackson, 1990; Rama, 1982, 1995; Schwartz, 1983; Verani, 1986; Yurkievich, 1984) en afirmar que las vanguardias literarias latinoamericanas tienen como interlocutor primario al modernismo. Las mismas, ponen en duda la validez de ciertas técnicas o usos del lenguaje, así como el valor de cierta manera particular de hacer arte. Si bien, no incluyen en su reflexión crítica a la institución artística (que todavía no estaba consolidada) ni tampoco ninguna reflexión acerca de los alcances del poder simbólico en los intercambios lingüísticos. Es decir, acerca de un poder que, según Pierre Bourdieu, sólo puede ser ejercido con la complicidad de quienes no quieren reconocer que están sujetos a dicho poder o que ellos mismos lo ejercen (Bourdieu, Language ... 164). Como lo examinaré más adelante, en la poesía de Vallejo hay una cierta reflexividad crítica que presupone, in nuce, un uso contra-hegemónico del poder simbólico. En este sentido, la desadecuación que experimenta Vallejo respecto a las demás vanguardias latinoamericanas puede ser vista como una huella estético-ideológica de este uso estratégico del poder simbólico.

Vallejo se ubica en úna situación intermedia entre Huidobro y Neruda, sus compañeros de generación. Sigue a Huidobro en la negación de la metáfora tradicional, (con sus furtivos comos iluminados), pero no deja de ser el poeta de la humanidad proletaria y de la 
solidaridad del género humano. ${ }^{3}$ Por otro lado, más allá de sus afinidades ideológicas, Vallejo no coincide con la estética política de Neruda y su poesía nunca se convierte en un vehículo político. Huidobro y Neruda practican una suerte de instrumentalización de la cultura - como recurso lúdico-formal, el primero, y como voluntad política, el segundototalmente ajena a la poesía de Vallejo y, en particular, a su interés por explorar las posibilidades utópicas que encierra la cultura.

Lo que Vallejo (1927 y 1928) escribe en sus artículos como corresponsal del semanario peruano Mundial y en sus cuadernos de apuntes (acerca de la emoción como esencial en la poesía, el poeta como creador de nebulosas, el contenido ampliamente humano del cubismo, el rechazo del surrealismo, o la manía metaforizante de los nuevos poetas) sirve como una sugerencia. Pero la ideología estética de Vallejo no tiene mejor banco de pruebas que su propia alquimia poética, la cual tiene su propia temporalidad. Por ejemplo, el nexo entre la poesía y la política, que es objeto de reflexión en su artículo Los artistas ante la política (1927), recién se transforma en materia poética en España, aparta de mi este cáliz, ${ }^{4}$ escrito diez años más tarde.

En el apartado que sigue me concentro en las estrategias simbólicas que constituyen el individualismo colectivo en la poesía de Vallejo.

LAS HUELLAS DEL INDIVIDUALISMO COLECTIVO

Un hombre pasa con un pan al hombro.

¿Voy a escribir, después, sobre mi doble?

César Vallejo, Poemas Humanos (1923-1938)

Vallejo es uno de los primeros en aceptar y acentuar la arbitrariedad del signo lingüístico. Rompe con las analogías de la imaginación simbolista para darles a éstas el máximo de inestabilidad y sutileza. Pasa de la polisemia modernista, todavía atada a una visión unívoca del mundo, a establecer nexos de sentido puramente subjetivos. Su hermetismo conceptual desplaza el mensaje poético hacia otros recursos expresivos de la lengua: sonoros, rítmicos, plásticos, gráficos, afectivos. Las anomalías lógicas, la pluralidad de sentidos que se entrecruzan, la múltiple libertad de desarrollo, sirven para aumentar la ambigüedad y la eficacia poética. Paradojalmente, el hermetismo conceptual de Vallejo alcanza una plena comunicación intuitiva.

Trilce (1922) lleva a cabo la revolución poética anunciada en los Heraldos negros (1918). En un medio tradicional y arcaizante, Vallejo forja una poesía de avanzada modernidad. Sus pautas expresivas (ilogicismo, disonancias, libertad de asociación,

\footnotetext{
${ }^{3}$ Refiriéndose al creacionismo de Huidobro, Vallejo dice: "No copia la vida, sino que la transforma (...) pero la transforma viciándola, falseandola" (E1 arte y la revolución, 27).

${ }^{4}$ Saúl Yurkievich dice: "Vallejo se expresa; manifiesta, pero no atestigua. Da su versión lírica de la guerra de España ... Utiliza según su arbitrio los recursos inherentes a la figuración literaria, inevitablemente ilusionista; los utilize sin sujetarlos a prurito testimonial. Vallejo plasma una fantasía basada en evidencias comprobables fabulándolas según su designio y diseño poéticos; las fabula sin desvirtuarlas". Véase “España, aparta de mi este cáliz: la palabra participante”, en Antonio Merino ed., 343.
} 
distorciones, desarticulación del lenguaje, polisemia, intensificación de lo arbitrario y aleatorio, etc.) trasmiten una visión relativa e inestable que disuelve las formas regulares, abandona los moldes prefijados, la rima, la regularidad estrófica, y adopta el verso libre, en el cual la forma y el contenido se amalgaman en completa correspondencia.

Después de la madurez poética alcanzada por Vallejo en Trilce (1922), resulta bastante difícil estimar qué le aportó su experiencia europea. Pienso que las experiencias revolucionarias europeas - la revolución rusa y la española - incorporaron en Vallejo un sentido del futuro inmediato y del cambio social imaginable. Pero las mismas poco contribuyeron a la imagen de comunidad que es característica de su poesía desde la época de Trujillo (Perú). Vallejo trasmuta la imagen de la comunidad local de Trujillo y establece los lugares de la memoria necesarios para constituir la representación de una comunidad socialista. Aquí, el lugar de enunciación es la especie humana. Lo cual, según Jameson, es característico de toda utopía.

La poesía de Vallejo rompe ataduras con el modernismo literario latinoamericano y se acerca a la modernidad europea. Sin embargo, mantiene con ésta una cierta distancia a la cual contribuye una doble valoración: la del cuerpo y la de una tradición cultural "local". 5 La valoración del cuerpo pone de manifiesto su sensibilidad poética materialista. La valorización de la "matriz andina" nutre su rechazo de la hegemonía racionalista, privilegia las emociones sobre la razón y constituye una intencionalidad utópico-política que trabaja en los límites de la tradición cultural disponible (Indio después del hombre y antes que él!). Esta valorización de la "matriz andina" se articula con la "diferencia americana", el carácter anti-europeo y la "poética del patrimonio" que Gordon Brotherston y Natalia Gómez (1996: 109-119) señalan en el poema "Telúrica y magnética".

En Los heraldos negros (1918) Vallejo sigue empleando el lenguaje de sus antecesores modernistas. El primer poema le da título a la obra y constituye una verdadera ars poética. Revela la crisis experimentada por Vallejo así como su insatisfacción frente a los límites del lenguaje. Los versos 7-8 del primer poema (Serán tal vez los potros de bárbaros atilas; $o$ los heraldos negros que nos manda la Muerte) suenan falsos, son los menos convincentes y también los más literarios. Estos versos están basados en imágenes derivadas de la lectura, expresan una cosmovisión todavía romántica en su esencia y contrastan con los versos 11 y 12 (Estos golpes sangrientos son las crepitaciones/de algún pan que en la puerta del horno se nos quema.) que emplean una imagen sencilla, sacada de la vida diaria. Esta imagen, eficaz como expresión de la vivencia poetizada, logra una comunicación directa y permite que el lector esté en mejores condiciones de recepcionar la vivencia trasmitida.

En el último verso: Hay golpes en la vida, tan fuertes .... Yo no sé, convergen el no saber y los límites del lenguaje. Es significativo que Vallejo cierre el poema con una expresión del lenguaje coloquial: Yo no sé. Esta ars poética incluye una mezcla de lenguajes y de fuentes a las cuales Vallejo acudirá en su obra posterior: la Biblia, las civilizaciones antiguas, las cosas de la casa, las situaciones sociales, y la experiencia

\footnotetext{
${ }^{5}$ Uso el término "local" para aludir a un problema de historia literaria que señala Cornejo Polar: la matriz andina de la obra ṕoética de Vallejo y su relación con "la bohemia de Trujillo" y con "la otra modernidad" que (a partir de la década del 20) se nutre de la conciencia histórica y de la tradición literaria nacionales (Cornejo Polar 147).
} 
cotidiana. El símil del verso 2 (Gopes como del odio de Dios), le da más fuerza al cierre(Yo no sé). Vallejo reduce el cristianismo a una fe entre otras. Esto se ratifica, en la frase del verso 9: los Cristos del alma. En suma, ni la religión crisitiana, ni la herencia racionalista de la cultura occidental, ni el lenguaje sirven para definir su experiencia poética. La ausencia de proyecto destaca, por contraste, el espacio poético de un proyecto a realizar.

Trilce (1922) despliega un estilo proteico, pone énfasis en las estructuras de la vida cotidiana y hace una original valoración poética del cuerpo. Por ejemplo, el poema XXVII muestra una escritura con un universo personalizado: verso libre, forma orgánica, estructura móvil para cada poema, aprovechamiento al máximo de los recursos sonoros y rítmicos, sintaxis poética con primacía de lo expresivo, metáforas puras, composición disonante. Los componentes de angustia, soledad y frustración, están anclados tanto en una sensibilidad poética materialista como en una situación objetiva. El individualismo colectivo de Vallejo constituye aquí una tensión, al mismo tiempo, emotivamente solidaria e históricamente imposible.

Vallejo usa la intuición poética para entablar las más libres asociaciones metafóricas:

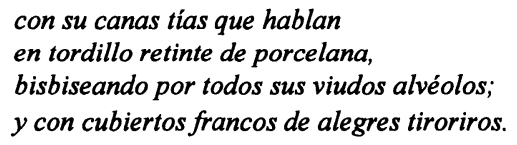

Toma palabras de todos los órdenes de las actividades humanas y sus prosaísmos y tecnicismos marcan una ruptura con la estética modernista. Así, incluye funciones orgánicas y partes anatómicas desvalorizadas por sus predecesores modernistas. Las palabras son, al igual que los símbolos, también objetos físicos y la lengua es, ella misma, una entidad material expresiva dotada de un dinamismo independiente (con sus canas tías que hablan / en tordillo retinte de porcelana). En suma, es la dimensión fónica (y no el sentido) la que determina la elección de los vocablos. De tal modo que aquí importa menos la sinestesia que la impresión acústica que el verso trasmite. La lengua del poema muestra la disonancia entre distintos niveles, (que van de lo coloquial a lo literario, de lo popular a lo culto) y conecta expresiones cotidianas y culteranas.

Sus imágenes no copian ni describen, sino que combinan, alusiva y libremente, los datos de la realidad empírica (bisbiseando por todos sus viudos alvéolos). Emplea tecnicismos (alvéolos) que hoy, seguramente, no resultan tan irritantes como en la década del veinte, pero que prueban la ampliación del registro poético que lleva a cabo Vallejo y su reacción en contra de una poesía del embellecimiento ilusorio y la imaginación evasiva. Dichos tecnicismos se incorporan en el texto y se conviertan en buenos trasmisores de la corriente emotiva. Por ejemplo, en el caso de alvéolos esta integración se logra porque la palabra está concertada no sólo por su significado sino también por su conveniencia fónica. Se encuentra en franca aliteración de bilabiales con otros vocablos del verso (bisbiseando por todos sus viudos alvéolos).

En su etapa europea la poesía de Vallejo aumenta el epesor conceptual, aunque éste ya está presente en Trilce cuando Vallejo acude al uso sistemático de los contrarios (cuyo antecedente es el conceptismo de Quevedo). Lo que separa a Vallejo de la sensibilidad 
estética modernista, así como de su "manierismo doctrinal" (Real de Azúa), ${ }^{6}$ es el sesgo estético-ideológico que oficia como telos en su exploración de las potencialidades utópicas encerradas en el lenguaje.

España, aparta de mí este cáliz (el texto de mayor expresividad y proyección ideológica de Vallejo), es un homenaje al sufrimiento armado y al protagonismo colectivo del pueblo español. Vallejo no menciona aquí héroes históricamente reconocibles, sino personajes anónimos convertidos en figuras emblemáticas de una nueva representación colectiva. Los protagonistas son líderes políticos, voluntarios de la República, gente común, mártires y trabajadores. Vallejo articula aquí su simpatía por los oprimidos con un uso secularizado y humanista del simbolismo religioso cristiano y constituye una imagendeseo antagónica al "individualismo posesivo". Esta imagen-deseo, que es evidente en la etapa europea ya está in nuce en el tratamiento de los temas indígenas, en el rechazo de la retórica liberal de los símbolos patrios (¿Cóndores? Me fregan los cóndores.) y, sobre todo, en las referencias al trabajo. La pre-historia de esta imagen-deseo la encontramos tanto en el énfasis que pone Vallejo en la cultura material y popular que caracterizó a los Andes como en su autodefinición como "indio" en el siglo veinte.

España, aparta de mi este cáliz rinde homenaje al heroísmo anónimo del pueblo español en lucha contra la barbarie nazi-fascista (El poeta saluda al sufrimiento armado). Vallejo expresa aquí su confianza en la solidaridad humana y advierte sobre los peligros de las dos Españas: Cuidate, España de tu propia España. El texto muestra una tensión entre lo individual y lo colectivo que es característica de toda la poesía de Vallejo. Por ejemplo, en Los heraldos negros, el dolor metafísco está asociado a la vivencia del cuerpo, en Poemas humanos, el sufrimiento individual adquiere una dimensión objetiva(Vallejo sufre solamente, es decir: no como Vallejo). Y, finalmente, en España, aparta de mi este cáliz, la experiencia individual de Vallejo interactúa con una interpretación histórico-dialéctica.

$\mathrm{El}$ interés que despliega Vallejo por las formas en las cuales se entrecruzan el significado y el poder es antagónico a la ficción jurídica y a las distancias encubridoras del "individualismo posesivo" liberal (MacPherson). La articulación entre significado y poder no significa en Vallejo una asimilación de las relaciones sociales y económicas a la cultura, o la reducción de la cultura a los sistemas simbólicos. Sus estrategias simbólicas remiten, más bien, al problema de la cultura como "whole way of life" (Williams 11). Pero, esta remisión no implica aquí un abandono del perspectivismo de clase o una reducción cultural del mismo, donde la política de la cultura se convierte en sustituto de una política de emancipación social. Tal como es el caso, por ejemplo, en el paradigma ascendente de los estudios culturales latinoamericanos a partir de la segunda mitad de los setenta.

Vallejo es inmune a cualquier instrumentalización de la cultura, incluida la que practican, por sustracción, los estudios culturales latinoamericanos contemporáneos. Si, gracias a los trabajos pioneros del historiador marxista J. P. Thompson, los estudios culturales británicos pasaron de la lucha de clases a la lucha sin clase, ${ }^{7}$ con el paradigma de

\footnotetext{
6 Para el "manierismo doctrinal" modernista véase Carlos Real de Azúa.

${ }^{7}$ El modelo interpretativo de la historia "desde abajo hacia arriba". J. P. Thompson privilegia la conciencia de clase y la experiencia versus la estructura y rechaza la pre-existencia de las clases económicas al margen de la experiencia histórica concreta de sus luchas. Por ejemplo; J.P Thompson dice: "The class experience is largeley determined by the productive relations ... Class consciousness
} 
los estudios culturales latinoamericanos contemporáneos se pasa a la lucha de clases sin clase y sin lucha. En Vallejo, como en Walter Benjamin, no exite este postivismo de la resignación, en ellos la tensión entre cultura y clase se articula con una conciencia de que la historia, hasta el presente, sólo existió como una continuidad de los vencedores en la cual todo documento de cultura es también un documento de barbarie. ${ }^{8}$

Benjamin le asigna particular importancia a la noción de discontinuidad histórica, la cual, según él, proviene no tanto de la ruputra de estructuras pre-dadas sino de la lucha contra las constricciones estructurales que el capital intenta importar a la actividad social. Dice Benjamin: "The sense that they are exploding the continuum of history is peculiar to revolutionary classes at the moment they enter into action" (Illuminations, 261). Paralelamente, Vallejo, enfrentado a la experiencia de la Revolución española, anticipa una modernidad cualitativa (como discontiuindad histórica) y constituye una imagen de la humanidad colectiva que no coincide totalmente con el imaginario de la Revolución española. Al hacer esto le da la razón a Mariátegui, quien supo ver en él "un espíritu purgado de colonialismo estético e intelectual".

La praxis poética de Vallejo muestra en acto cómo el significado no es una propiedad estable o invariante de un producto lingüístico sino un fenómeno fluctuante. Vallejo coincide en esto con desarrollos teóricos recientes del concepto de ideología ${ }^{9}$ y del poder simbólico. ${ }^{10}$ Estas investigaciones focalizan cómo el significado sirve para mantener las relaciones de dominación y explotación. Así, en los intercambios lingüísticos, con palabras de Bourdieu: "authority comes to language from outside" (Bourdieu, Language ... 109). Terry Eagleton dice que el concepto de ideología no implica una supuesta esencia sino un entramado superpuesto de "parecidos de familia" el cual, remite no sólo a los signos, significados y valores que ayudan a reproducir un poder social dominante, sino también: "to any significant conjuncture between discourse and political interests" (Eagleton 221-22).

\section{POESÍA Y PODER SIMBÓLICO}

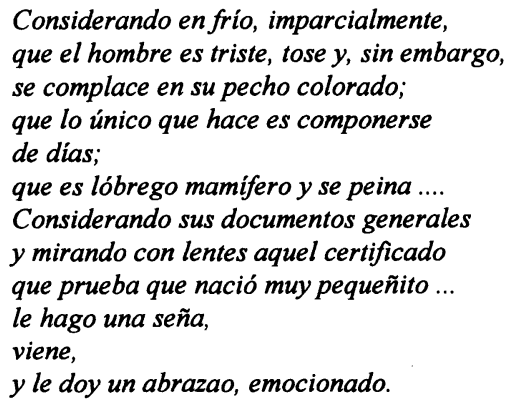

is the way in which these experiences are handled in cultural terms: embodied in traditions, value systems, ideas and institutional forms" (Thompson 10).

${ }^{8}$ Para la evidencia de esto en Vallejo véase Gordon Brotherson y Natalia Gómez.

${ }^{9}$ Véase J. B. Thompson y Terry Eagleton.

${ }^{10}$ Véase Bourdieu, Language and Symbolic Power, 163-170. 


\section{Qué más da! Emocionado ... Emocionado ... \\ César Vallejo, Poemas humanos (1923-1938)}

Según Bourdieu, en Language and Symbolic Power, el lenguaje forma parte del modo de vida de un grupo social y sirve, esencialmente, a fines prácticos. Bourdieu se opone así a cualquier filosofía intelectualista que considere el lenguaje como un objeto de entendimiento y no como un objeto de acción. Cada interacción lingüística por personal o insignificante que ella sea, conlleva las huellas de la estructura social que dicha interacción expresa y ayuda a reproducir. Así, el poder simbólico es una dimensión transversal a los distintos intercambios lingüísticos $\mathrm{y}$, paralelamente, cada acto lingüístico tiene la potencialidad de un acto de poder (Bourdieu, Language ... 145). Las relaciones lingüísticas son siempre relaciones de poder simbólico en las cuales las relaciones de fuerza entre los hablantes y sus respectivos grupos son puestas en acto de una forma transfigurada o denegatoria. Bourdieu dice:

Every linguistic exchange contains the potentiality of an act of power ... This potentially can be "bracketed".... However, even in these cases, the refusal to wield domination can be part of a strategy of condescension or a way of taking violence to a higher degree of "denegation" and dissimulation, a means of reinforcing the effects of misrecognition and thereby of symbolic violence (Bourdieu, Language ... 192, subrayado mío).

Los nueve monstruos, Considerando en frio imparcialmente ...., Voy a hablar de la esperanza, son poemas que parecen construidos con un andamiaje conceptual, pero que nunca se condensan en juicios puros, nunca son axiomáticos. Su eficacia poética está en relación directa con una pluralidad de lecturas simultáneas que dichos poemas no solamente admiten, sino que, sobre todo, provocan. Esta simultaneidad, contribuye a desmontar los discursos de la vida social, pone de manifiesto su carácter reificado, y sugiere las posibilidades no realizadas que dichos discursos encierran.

La reificación, una de las modalidades bajo las cuales funciona la ideología, consiste en representar un estado de cosas histórico y transitorio como si fuera permanente, ahistórico o natural. ${ }^{11}$ En Vallejo, la puesta en evidencia de los mecanismos de la reificación ${ }^{12}$ opera como una hermenéutica negativa. Pero Vallejo despliega, también, una hermenéutica positiva que anticipa una imagen del futuro. Esta doble hermenéutica, negativa y positiva, es la que marca el espacio simbólico de una representación todavía inimaginable: la del hombre colectivo. La tensión estético-ideológica que inaugura antagoniza a la distinción formal entre lo público y lo privado característica del imaginario liberal. ${ }^{13}$

Jean Franco dice con razón que en Vallejo: "la dislocación del lenguaje y la ruptura de las convenciones, es lo que hace de él un poeta verdaderamente extraordinario" (Franco 134). Estas palabras resultan iluminadoras respecto a la hermenéutica negativa de Vallejo,

\footnotetext{
"Para mayor información sobre esta idea véase Thompson, 28-122.

12 Para los mecanismos de reificación en la formación del campo literario latinoamericano véase Rama, La ciudad letrada.

${ }^{13}$ Véase la impugnación gramsciana de la rígida contraposición liberal entre lo público y lo privado en Antonio Gramsci, Note sul Machiavelli, sulla politica e sullo stato moderno, 29-62; 125-133.
} 
la que pone al descubierto los mecanismos de la reificación en el lenguaje. Pero es, precisamente, la dialéctica de una hermenéutica negativa otra positiva, la que permite deslindar la especifidad de las estrategias simbólicas de Vallejo de las de otras vanguardias con las cuales guarda parecidos de familia. ${ }^{14}$ Es cierto que Vallejo desarticula los mecanismos de la reificación cristalizados en el lenguaje. Esto lo hace mediante el procedimiento de levantarles su acta poética. Pero, también, Vallejo constituye una imagendeseo colectiva. En ella, lo viejo y lo nuevo están interrelacionados ${ }^{15}$ y la tradición disponible nutre (como memoria cultural incorporada) la imagen utópica de una modernidad cualitativa. En suma, la poesía "intrahistórica" de Vallejo constituye una imagen-deseo colectiva en la cual la modernidad socialista es una categoría cualitativa y no cronológica. ${ }^{16}$

Esta constitución poética de una imagen-deseo colectiva tiene una gran proyección dentro del imaginario social hispanoamericano. Vallejo hace conexiones insospechadas e insospechables que, una vez hechas, se vuelven ineludibles. Por ejemplo, en el primer poema de España, aparta de mí este caliz Vallejo dice: Quevedo, ese abuelo instantáneo de los dinamiteros. Este verso abre (emotiva e intuitivamente) un sistema de vasos comunicantes entre Quevedo, ${ }^{17}$ la otra España y los revolucionarios españoles. Vallejo hace aquí una interpretación que exige reconocimiento y que cuestiona el carácter reificado de la tradición. A través de esta interpretación la tradición cultural cobra vueloy la modernidad socialista hecha raíces. España aparta de mí este caliz articula la modernidad socialista de la Revolución Española con la otra España y con la memoria incorporada de Trujillo(Perú). Para Mariátegui la modernidad socialista pasa por "peruanizar al Perú", para Vallejo: ¿pasa por peruanizar el imaginario de la República española con su memoria cultural incorporada de Trujillo?

El hermetismo solidario de Vallejo constituye una imagen colectiva al margen de cualquier "estrategia de condescendencia" (Bourdieu). El mismo neutraliza el obstáculo que Gramsci señaló respecto a las relaciones sociales entre intelectuales y masas dentro de una formación social nacional. ${ }^{18}$ Según Gramsci, todos los hombres son intelectuales pero

\footnotetext{
${ }^{14}$ Antonio Cornejo Polar dice: "después de haber llevado hasta el final la experiencia absolutamente moderna de Trilce antes de llegar a Europa, Vallejo bien podia observar sin entusiasmo, y más bien con escepticismo, el espíritu renovador del vanguardismo europeo: el suyo había sido, y seguía siendo, más audaz y más consistente" (149).

${ }^{15}$ Esta constitución de una imagen-deseo vincula a Vallejo con los historiadores marxistas británicos que le asignan particular importancia a la producción social del deseo en la formación de la conciencia de clase. Véase Harvey J. Kaye.

${ }^{16}$ Para los alcances de esta intepretación de la modernidad socialista como una categoría cualitativa en el el debate de las ideas contemporáneo (en particular en el debate acerca de la modernidad y la modernización en Marshall Berman y Perry Anderson) véase Peter Osborne.

${ }^{17}$ Según Xavier Abril: "El rastro más saliente de Quevedo en Vallejo es el carácter conceptista" (168).

${ }^{18}$ Gramsci dice: "The intellectual do no come from de people, even if by accident some of them have origins among the people. They do no feel tied to them (rhetoric apart), they do not know and sense their needs, aspirations and feelings. In relation to the people, they are something detached, without foundations, a caste and not an articulation with organic functions of the people themselves" (Gramsci, Selections ... 209).
} 
no todos los hombres tienen en la sociedad la función de intelectuales (Gramsci, Selections ... 9). La interpelación y/o constitución poética de un sujeto colectivo que hace Vallejo "siente" con los sectores populares y las clases subalternas. Su individualismo colectivo constituye un vínculo de solidaridad social que incorpora una dimensión utópica no a través del propio ejercicio de la función intelectual sino como una forma "naturalmente humana" de la sensibilidad.

En Masa (España, aparta de mí este cáliz) Vallejo articula lo social y lo simbólico constituyendo una imagen-deseo colectiva que potencializa al máximo los recursos de la tradición cultural hispanoamericana históricamente inscriptos en el lenguaje. Anticipa simbólicamente una resemantización política de dichos recursos $\mathrm{y}$, con palabras de Benjamin, logra "provocar una demanda cuando la hora de sus satisfacción plena todavía no ha sonado"(Benjamin, Discursos interrumpidos 49). En el apartado siguiente examinaré esta dialéctica de ideología y utopía ${ }^{19}$ usando como herramientas conceptuales los análisis de la función utópica de la ideología en Fredric Jameson.

IDEOLOGIA Y UTOPIA

\author{
Al fin de la batalla, \\ y muerto el combatiente, vino hacia él un hombre, \\ le dijo: " No mueras; te amo tanto!" \\ Pero el cadáver, ihay! siguió muriendo. \\ César Vallejo, Masa
}

The future lies entangled in that unrepresentable outside like so many linked genetic messages.

Fredric Jameson

El poema Masa de Vallejo constituye un espacio literario privilegiado para hacer una homología con las reflexiones teóricas de Fredric Jameson acerca de la dialéctica de ideología y utopía. En este poema Vallejo convierte la predicación en predicción y produce una imagen-deseo del hombre colectivo de gran proyección y fuerza anticipatoria dentro del imaginario hispanoamericano. Masa es una parábola basada en la historia bíblica de la resurrección de Lázaro (Juan, 11,43-44) que presenta una visión profética de la victoria del socialismo. Vallejo usa las connotaciones simbólicas de un lenguaje cristiano para cantar la redención del hombre en este mundo. En un tono profético - cuyo lugar de enunciación es la especie humana en su conjunto ${ }^{20}$ - anuncia el advenimiento de la nueva humanidad socialista.

\footnotetext{
${ }^{19}$ Sigo aquí los análisis que hace Fredric Jameson en The Political Unconscious, Narrative as a Socially Symbolic Act y en The Seeds of Time. En este último libro Jameson dice: "Utopian content of a given text in the present should never be understood as somehow foreclosing or excluding its simultaneous ideological content and function in that same present ... in a fallen or class society, science, the Utopian, and indeed everything else of value, must also and always simultaneously function as an ideology" (77).

${ }^{20}$ Según Jameson, esto es lo característico de toda utopía: "Utopia necessarily takes the point of view of the species upon human history, thus emptying it of much that we consider not merely historical but irreplaceable significant in human life" (Jameson, The Seeds of Time 123).
} 
El sujeto del poema es un obrero muerto en combate, voluntario de la República española, que ha tomado las armas para defender y construir los valores de la nueva sociedad socialista. Se trata de un hombre que ha superado el individualismo capitalista y que piensa y actúa con mentalidad colectiva. Su muerte tiene algo de ejemplar, ya que significa el sacrificio personal por el bien de la humanidad en su conjunto. Su ejemplo inspira respuestas fraternales en los otros milicianos y dichas respuestas van de un caso aislado a millones. El poema cobra así una tensión creciente, cuya progresión emocional se resuelve en la última estrofa:

\section{Entonces todos los hombres de la tierra \\ le rodearon; les vió el cadáver triste, emocionado; incorporóse lentamente, \\ abrazó al primer hombre; echóse a andar}

Esta "resurrección no prodigiosa"21 tiene lugar gracias a la intervención del amor colectivo. El poema descarta la intervención sobrenatural, opone a la muerte la totalidad del género humano, y sugiere que el amor individual resulta ineficaz y que el sacrificio del miliciano será en vano (no sólo sigue muerto sino que va muriendo cada vez más) mientras prevalezca el individualismo en el mundo. La resurrección, fruto del amor colectivo, es una metáfora hiperbólica de la capacidad transformadora del socialismo para cambiar las condiciones de vida. En el poema no figura ninguna referencia histórica ni geográfica que lo sitúe dentro del contexto de la guerra civil española. La única alusión es la mención significativa del primer verso: Al fin de la batalla ...

Masa tiene una enorme proyección simbólica dentro del imaginario social hispanoamericano. Vallejo articula la recurrente conflictiva de trádición y modernidad que se vuelve explícita en la cultura política hispanoamericana a partir de la disolución de la unidad del Estado colonial y la iglesia católica. ${ }^{22}$ Masa recupera - a través de su mezcla de los lenguajes - una imagen de comunidad ajena a la distinción liberal entre lo público y lo privado y la articula con el poder simbólico del lenguaje de la religión católica, como fuerza social histórica significativa dentro del mundo de habla hispana. El resultado de esta articulación poética es que la tradición hispanoamericana se vuelve una memoria cultural abierta. Es decir, una memoria cultural no cristalizada ni en una invariante ni en un estereotipo. ${ }^{23}$

El poema marca una opción privilegiada por el pobre con una fuerte connotación bíblica y evangélica. Tal como lo hará, a partir de los años sesenta, la teología de la liberación en América Latina. ${ }^{24}$ En el espacio simbólico de Masa tiene lugar la convergencia anticipada de las dos grandes construcciones de identidad colectiva que florecieron en

\footnotetext{
${ }^{21}$ Alberto Escobar observa el plano de realidad en que se desenvuelve el relato poetizado en Masa y dice que se trata de una construcción organizada sobre un eje imaginario que presupone un contexto socio-histórico concebido como un nivel de abstracción más alto (318-322).

${ }^{22}$ Véase Dermont Keogh.

${ }^{23}$ Para un ejemplo en contrario véase Howard J. Wiarda (comp.).

24 Para la teología de la liberación en América Latina véase Edward L. Cleary ed.
} 
América Latina a partir de los años sesenta: el marxismo latinoamericano ${ }^{25}$ y la teología de la liberación. En tiempos de escasa visibilidad social, del avance conjunto de la hegemonía neo-liberal y la de las iglesias protestantes en América Latina, ${ }^{26}$ y del eclipse de la utopía, ¿será Vallejo el abuelo instantáneo de la posible convergencia de esas dos grandes construcciones de identidad colectiva?

La función utópica que despliega el poema Masa resulta compatible con las reflexiones acerca de la dialéctica ideología-utopía en Fredric Jameson. ${ }^{27}$ Según Jameson, la negación contemporánea del concepto de totalidad está relacionada con la crisis de representación que es característica del postmodernismo como lógica cultural del capitalismo tardío. Dice Jameson:

the thinking of totality itself ... has the palpable benefit of forcing us to conceive of at least the possibility of other alternate systems, something we can now identify as our old friend Utopian thinking (Jameson, The Seeds of Time 70).

Dentro de una historia cuya dinámica representacional —-como Jameson indica - "se nos escapa", el trazado de mapas cognitivos representa "the absent first step of renewed praxis" (Jameson, The Seeds of Time 71). Esta política del trazado de mapas cognitivos se inscribe dentro de un perspectivismo de clases sociales: "cognitive mapping" es en realidad "a code word for "class consciousness"" (Jameson, "Marxism ..." 44). Dicha política apunta a constituir una nueva representación (todavía inimaginable) que permita desarrollar estrategias políticas globales alternativas al capitalismo. Jameson no sólo le atribuye a la utopía una función hermenéutica positiva - dentro de la tradición intelectual del marxismo ${ }^{28}$ sino que, además, señala el carácter utópico de toda experiencia colectiva. Dice Jameson:

The concept of class is thus the space in which, if anywhere, a Marxian version of the hermeneutics of meaning, of some non instrumental conception of culture, may be tested ... effectively ideological is also, at the same time, necessarily Utopian (The Political Unconscious 286).

Así, la dialéctica de ideología-utopía anticipa - "like so many linked genetic messages"- un nuevo modo de representación en el cual podamos recuperar (individual y colectivamente) nuestra capacidad de actuar (Jameson, "El posmodernismo ..." 173). Por su parte, Masa constituye una imágen del hombre colectivo que anticipa, con palabras de

\footnotetext{
${ }^{25}$ Para el marxismo latinoamericano véase Agustín Cueva "El marxismo latinoamericano: historia y problemas actuales".

${ }_{26}$ Véase Atilio Borón y David Stoll.

${ }^{27}$ Véase Jameson, The Political Unconscious 281-299 y The Seeds of Time.

${ }^{28}$ Para mayor información sobre el desarrollo de estrategias políticas globales alternativas al capitalismo véase Jameson, "El posmodernismo o la lógica cultural del capitalismo tardío" y "Cognitive Mapping". Igualmente, Jameson se refiere a la crítica de Marx al utopismo y dice: "his objection that the Utopians themselves were not sufficientely concerned with the implementation and realization of their projects is only true politically and not socially or ontologically ... Marx himself is meanwhile Utopian in precisely the separation of the realms of Necessity and Freedom" (Jameson, The Seeds of Time 59).
} 
Jameson, "the logic of a collectivity which has not yet como to being" (The Political Unconscious 286). Hay una posible homología entre la configuración estético-ideológica del individualismo colectivo en la poesía de Vallejo y la "solución" de Jameson respecto a la necesidad de un vínculo pre-político de solidaridad social. Dice Jameson:

My own "solution"... affirms the Utopian character of all collective experience (including those of fascism and the various racism) but stresses the requirement of an existential choice of solidarity with a specific concrete group: on this non formalist view, therefore, the social solidarity must precede the ethicopolitical choice and cannot be deduced from it (The Seeds of Time 43-44, énfasis mío).

En suma, la praxis poética de Vallejo y el trazado de mapas conginitivos en Jameson hacen una interpretación no instrumentalista de la cultura enmarcada dentro de un perspectivismo de clases sociales. Ambos le asignan importancia anticipatoria a la función utópica de la ideología en lo que respecta a la constitución de un vínculo pre-político de solidaridad social. En Vallejo, el espacio simbólico de este vínculo pre-político lo constituye la configuración estético-ideológica de su individualismo colectivo.

\section{CONSIDERACIONES FINALES}

En conclusión, las estrategias simbólicas que constituyen el individualismo colectivo en la obra poética de Vallejo: (a) articulan una imagen alternativa al "individualismo posesivo" sin cristalizar al presente histórico en una invariante o en un testimonio; (b) usan el poder simbólico para conservar (transformando) los significados culturales de la tradición hispanoamericana, (evitando así su reificación como memoria cultural); (c) despliegan una función utópico-ideológica que anticipa el espacio simbólico de una nueva representación colectiva todavía inimaginable.

El individualismo colectivo en la poesía de Vallejo - "una forma natural y simplemente humana de la sensibilidad"- despliega una dimensión utópica anticipatoria que alcanza connotaciones contemporáneas. Mi objetivo en este trabajo fue focalizar dicha configuración estético-ideológica y sugerir su proyección dentro del imaginario social hispanoamericano.

\section{BiBLIOGRAFÍA}

Abril, Xavier. Vallejo. Buenos Aires: Ediciones Front, 1956.

Azúa, Carlos Real de. "El modernismo literario y las ideologías". Escritura 3 (1977): 4176.

Benjamin, Walter. Discursos interrumpidos. Madrid: Taurus, 1973. Illuminations. Stocken, NY: 1968.

Charles Baudelaire: A Lyric Poet in the Era of High Capitalism. London: Verso, 1973.

Borón, Atilio. Estado, Capitalismo y Democracia en América Latina. Buenos Aires: Ed. Imago Mundi, 1992.

Bourdieu, Pierre. Language and Symbolic Power. Cambridge, MA: Harvard University Press, 1991. 
The Field of Cultural Production. Great Britain: Polity Press, 1933.

"Strategies de Reproduction et Modes de Domination". Actes de la Recherche 105 (1994): 3-12.

Brotherston Gordon y Natalia González. "La poética del patrimonio: 'Telúrica y magnética' de Cesar Vallejo". Cuadernos Hispanoamericanos 548 (febrero 1966): 109-119.

Cleary, Edward, ed. Born of the Poor: the Latin American Church Since Medellin. Notre Dame: University of Notre Dame Press, 1990.

Cueva, Agustín. "El marxismo latinoamericano: historia y problemas actuales". Homines 6 (1989): 428-411. Ideología y sociedad en América Latina. Montevideo: Ediciones de la Banda Oriental, 1988.

Cornejo Polar, Antonio. La formación de la tradición literaria en el Perú. Lima: Centro de Estudios y Publicaciones, 1989.

De Campos, Haroldo. "Superación de los lenguajes exclusivos". América Latina en su Literatura. César Fernández Moreno ed. México: Siglo XX, 1978. 279-300.

Eagleton, Terry. Ideology: An Introduction. London: Verso, 1991.

Escobar, Alberto. Cómo leer a Vallejo. Lima: P. L. Villanueva Ed., 1973.

Flores, Angel, ed. Aproximaciones a César Vallejo. New York: Las Américas, 1971.

Franco, Jean. "César Vallejo". A. Merino (ed.), En torno a César Vallejo. Madrid: Ed. Júcar, 1988.

Forster, M. and K. D. Jackson. Vanguardism in Latin American Literature. An Annotated Bibliographical Guide. New York: Greenwood, 1990.

Gramsci, Antonio, Antonio Gramsci. Selections from Cultural Writings. G. Forbes/G. Nowell-Smith. Cambridge: Harvard University Press, 1991.

Selections from the Prison Notebooks. Q. Hoare/G. Nowell-Smith. New York: International Publishers, 1989.

Note sul Machiavelli, sulfa politica e sullo stato moderno. Torino: Einaudi, 1955.

Jameson, Fredric. The Political Unconscious. Narrative as a Socially Symbolic Act. Ithaca,

NY: Cornell University Press, 1981.

"El posmodernismo o la lógica cultural del capitalismo tardío". Casa de las Américas 155-156 (1986): 141-173.

"Cognitive Mapping". Marxism and the Interpretation of Culture. Cary Nelson and

Lawrence Grossberg eds. Urbana: University of Illinois Press, 1988. 347-360.

"Marxism and Postmodernism". New Left Review 176 (1989): 31-45.

Postmodernism; or, The Cultural Logic of Late Capitalism. Durham: Duke

University Press, 1992.

The Seeds of Time. New York: Columbia University Press, 1994.

Kaye, Harvey J. The Education of Desire. Marxist and the Writing of History. New York/ London: Routledge, 1992.

Keogh, Dermot. Church and Politics in Latin America. New York: St. Martin's, 1990.

Macpherson, C. B. The Political Theory of Possesive Individualism. Hobbes to Locke.

London: Oxford University Press, 1962.

Machín, Horacio. “Conversación con Fredric Jameson”. Nuevo Texto Crítico 7 (1991): 317. 
Mariátegui, Juan C. Siete ensayos de interpretación de la realidad peruana. Lima: Empresa Editora Amauta, 1959. Peruanicemos al Perú. Lima: Empresa Editora Amauta, 1970. Amauta (1926-1938), 2v. 32 Nos. Ed. fascimile. Lima: Empresa Editora Amauta. Merino, Antonio ed. En torno a César Vallejo. Madrid: Ed. Júcar, 1988.

Osborne, Peter. "Modernity is a Qualitative, Not a Chronological Category". New Left Review 192 (March/April 1992): 65-84.

Pizarro, Ana, org. América Latina: Palavra, Literatura e Cultura, v.3. São Paulo: Editora da Unicamp, Fund. Memorial de América Latina, 1995.

Rama, Ángel. La novela latinoamericana 1920-1980. Colombia: Instituto Colombiano de Cultura, 1982.

La ciudad letrada. Hanover: Ed. del Norte, 1984.

La riesgosa navegación del escritor exilado. Montevideo: Arca, 1995.

Schwartz, Jorge. "La Vanguardia en América Latina: una estética comparada". Rev. de la Univ. de México 21 (1983): 12-16.

Stoll, David. Is Latin America Turning Protestant?. Berkeley and Los Angeles: University of California Press, 1990.

Thompson, John B. Ideology and Modern Culture. Stanford: Stanford University Press, 1990.

Thompson, J. P. The Making of the English Working Class. London: Pelican Books, 1968.

Vallejo, César. Obra completa. Lima: Mosca Azul Editores, 1974.

Verani, Hugo. Las vanguardias literarias en hispanoamérica. Manifiestos, proclamas y otros escritos. Roma: Bulzoni, 1986.

"Estrategias de la vanguardia". Ana Pizarro, org., América Latina: Palavra, Literatura e Cultura, v. 3 (1995): 75-87.

Wiarda, Howard J. (comp.). Politics and Social Change in Latin America. The Distinct Tradition. Amherst: Masachusetts University Press, 1992.

Williams, Raymond. Culture. London: Fontana, 1981.

Yurkievich, Saúl. A través de la trama, Barcelona: Muchnik, 1984.

"Los avatares de la Vanguardia". Revista Iberoamericana 118-119 (1982): 351366. 
